\title{
Enduring Design Challenges in Western Roleplaying Video Games
}

Paul Ralph, Kafui Monu

\begin{abstract}
A roleplaying game (RPG) is a fuzzy class of video games that includes at least three quite different subclasses. This paper focuses on one of these subclasses, Western RPGs, which stand out for their focus on discovery and expression. It proposes a definition of a Western RPG as a video game that: encourages players to assume the part(s) of one or more virtual characters, in large open environments, with plentiful freedom of expression throughout game narratives. This definition is evaluated against archetypal Western RPGs and related genres. The paper further identifies three enduring challenges in Western RPG design: (1) bipolar morality scales, (2) quest distribution, (3) oversimplified difficulty scaling. Concrete suggestions for overcoming these challenges are provided.
\end{abstract}

Keywords: Roleplay, open-world, game design, morality, alignment, quests, difficulty scaling 


\section{Introduction}

After a brief decline in the 1990s, roleplaying video games (RPGs) have regained substantial popularity. The Elder Scrolls V: Skyrim (2011), for example, sold over 20 million copies for over US\$1 billion (Grandstaff, 2013) and was still one of the top 50 sellers on Steam five years later (Valve, 2017). With this resurgence, however, RPGs split into at least three evident sub-genres-Action, Japanese, and Western.

Western Role Playing Games (WRPGs), also called Open World RPGs, including The Elder Scrolls V: Skyrim (2011), Mass Effect 3 (2012), Dragon Age: Inquisition (2014) and Fallout 4 (2015), are especially interesting from a design perspective for at least three reasons:

1. They are mechanically and aesthetically complex

2. They are named in a misleading way

3. Even the best WRPGs have major unresolved design challenges

While much has been written about tabletop roleplaying games (cf. Peterson, 2012) and some research investigates roleplaying video games (e.g. Fine, 2002; Yee, 2006), we are not aware of any existing literature exploring the defining characteristics and outstanding design issues in Western Role Playing Games.

The purposes of this essay, therefore, are: (1) to explore what we mean by "Western Roleplaying Game" and (2) to explore unresolved design challenges in WRPGs. However, because game studies is a relatively young discipline with relatively little consensus on terminology, we first describe our perspective on game design and define key terms used throughout this article. Next, we describe the problem with game genres and then propose and evaluate a definition of WRPG. Then we analyse three challenges in WRPG design. Finally, we conclude with a summary of our contribution.

\section{Game Design Theory}

Like many other young fields, game studies lacks consensus on key terminology. In previous work, we therefore synthesised existing literature into a descriptive theory of video games, which defines the concepts needed to describe games, delineate genres and analyse design challenges. In this section, we define and describe key terms to clarify our subsequent arguments, not to present the definitions as correct or some kind of absolute truth.

The Unified Theory of Digital Games (Figure 1; Table 1) defines a game as a both a system for structuring play and an event where one or more players interact with such a system (Ralph \& Monu, 2015). Games evoke emotional responsesaesthetics-in players. Note: In most fields, aesthetics refers to style or how something looks; in game design however, aesthetics denotes something closer to mood or atmosphere in literature. We can use horror, drama and comedy, for example, to describe both the aesthetics of some games and the atmospheres of some books. However, because games are interactive, they can have aesthetics that rarely or never occur in literature, for instance, challenge (game as obstacle course), 
expression (game as self- discovery) and submission (game as mindless pastime or to-do list) (Hunicke, LeBlanc, \& Zubek, 2004).

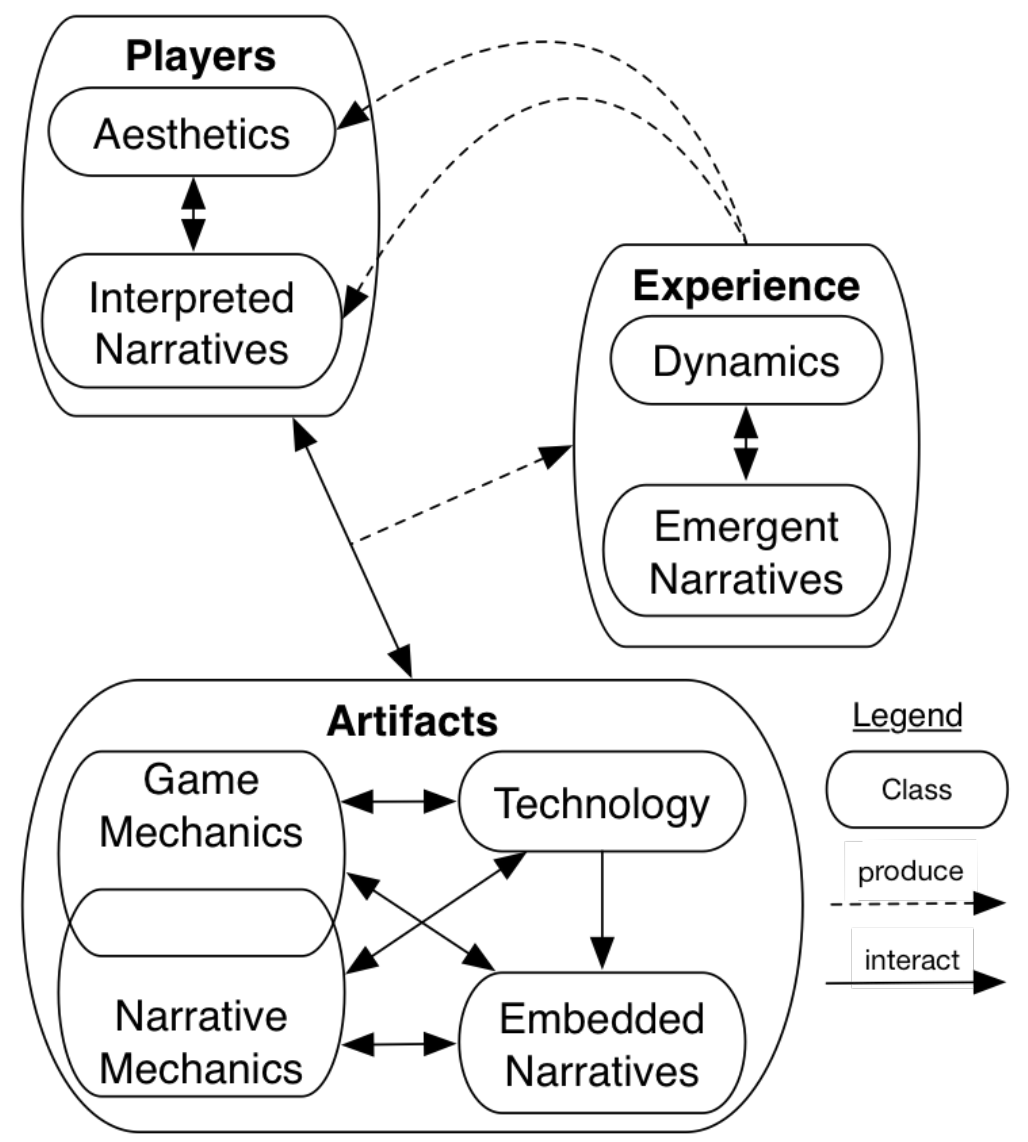

Figure 1. The Unified Theory of Digital Games (Ralph \& Monu, 2015)

Game aesthetics are influenced by game dynamics-the emergent interactions between players and game system. Suppose that a game involves numerous repetitive tasks, for example, tapping an icon every five minutes to collect resources or repeatedly fighting identical enemies to gain experience points. This kind of repetitive goal-oriented behaviour (known as grinding dynamics), engender an atmosphere of just doing what the game tells you to do (i.e. a submission aesthetic).

Dynamics, in turn, are influenced by game mechanics - the elements that create the game's challenges. For example, suppose a hoobat has a 1 in 20 chance of dropping a hoobat claw, and the player needs three hoobat claws to make the powerful hoobat gauntlet weapon. Combining the random loot drop mechanic and the crafting mechanic encourages the player to grind (spend hours wandering around fighting hoobats). Schell (2008) identifies six categories of game mechanics: "space", "objects", "actions", "rules", "skill" and "chance".

Meanwhile, as players interact with games, meaningful sequences of events may arise. Jenkins (2004) called these emergent narratives to distinguish them from stories baked into a game by its developers, or embedded narratives. Game developers use narrative mechanics including cut scenes and dialogue to deliver embedded narratives and encourage emergent narratives. Players may form diverse interpretations of both emergent and embedded narratives, i.e. interpreted narratives 
(cf. Pearce, 2004). Furthermore, some elements can be game mechanics and narrative mechanics simultaneously; for example, a quest may present challenges and convey an embedded narrative (Ralph \& Monu, 2015).

Table 1

Definitions (adapted from Ralph \& Monu, 2015)

\begin{tabular}{|c|c|}
\hline Element & Definition \\
\hline Artifacts & $\begin{array}{l}\text { elements related to artificial objects and systems used to structure play (cf. } \\
\text { Deterding, Dixon, Khaled, \& Nacke, 2011) }\end{array}$ \\
\hline Players & $\begin{array}{l}\text { individual, human or non-human agents who use game artifacts to structure } \\
\text { play }\end{array}$ \\
\hline Experience & $\begin{array}{l}\text { elements related to events, behaviour and meaning that emerge from player- } \\
\text { artifact interaction }\end{array}$ \\
\hline $\begin{array}{l}\text { Game } \\
\text { Mechanics }\end{array}$ & $\begin{array}{l}\text { elements used by game developers to create and manipulate challenges for } \\
\text { players }\end{array}$ \\
\hline $\begin{array}{l}\text { Narrative } \\
\text { Mechanics }\end{array}$ & elements used by game developers to advance the plot of the game \\
\hline Technology & $\begin{array}{l}\text { tangible and intangible artifacts used to deliver game elements or play the } \\
\text { game }\end{array}$ \\
\hline $\begin{array}{l}\text { Embedded } \\
\text { Narratives }\end{array}$ & $\begin{array}{l}\text { stories told by developers to players through narrative mechanics and } \\
\text { gameplay }\end{array}$ \\
\hline Dynamics & $\begin{array}{l}\text { emergent behaviour of both the game and the player during player-game } \\
\text { interaction }\end{array}$ \\
\hline $\begin{array}{l}\text { Emergent } \\
\text { Narrative }\end{array}$ & $\begin{array}{l}\text { a meaningful sequence of events that emerges during player-game } \\
\text { interaction }\end{array}$ \\
\hline Aesthetics & the emotions evoked by a game \\
\hline $\begin{array}{l}\text { Interpreted } \\
\text { Narrative }\end{array}$ & $\begin{array}{l}\text { a player's mental representations and interpretations of a game's intended or } \\
\text { emergent narratives }\end{array}$ \\
\hline
\end{tabular}

Game mechanics, narrative mechanics and embedded narratives are all delivered through technologies (e.g. buttons, headphones). Technologies, mechanics and narratives all interact in ways we do not fully understand.

Armed with this vocabulary, we can now attempt to define Western Role Playing Games, and explore their design challenges.

\section{Classification Theory and the Problems with Game Genres}

The term "Roleplaying Game" is obviously problematic because it could technically apply to an enormous variety of games. People play roles in first-person shooters (e.g. the Call of Duty series), platformers (e.g. the Rayman series) and even arcade games (e.g. the Pac-Man series), which obviously are not what the term 'RPG' attempts to denote. 
Several types of RPGs have emerged including Action (ARPG), Japanese (JRPG) and Western (WRPG). JRPG and WRPG are similarly problematic because Japanese studios sometimes make western-style RPGs (e.g. the Dark/Demon Souls series) and western companies sometimes make Japanese-style RPGs (cf. Bailey, 2012). This raises a deeper issue of what makes a good class.

Classification is a fundamental cognitive process for reducing cognitive load and supporting inferences (Rosch, 1978). In classification theory, an instance is an individual thing, while "a class is an abstract description of a set of properties shared by a set of instances" (Parsons \& Wand, 2008, p. 841). Good classes represent instances that are similar in some way and help us make useful inferences about their contents or instances (Parsons \& Wand, 2008). Games made in western countries is not a good class because it does not represent similar instances or support further useful inferences. Flight Simulator is a better class because we can infer that instances will all have take-off, flying, landing, approximated flight controls (depending on aircraft), weather, turbulence, etc. In the nomenclature of classification theory, we can infer properties of instances of the flight simulator class beyond the necessary conditions for class membership.

Literary genres including comedy, tragedy, drama, romance, horror, and fantasy are named after what we would call aesthetics in game studies. Comedies attempt to be funny, tragedies tragic, dramas dramatic, romances romantic, etc. These genres are mostly good classes because they help us infer whether the work matches our tastes. Stories written in third-person omniscient point of view is contrastingly a poor class because we cannot infer much from it, including whether we will like the story.

Game genres have been named after mechanics (platform games), dynamics (turned-based strategy games), previous games ("Roguelikes", "Metroidvania"), aesthetics (horror games), country of origin (Japanese RPGs) and even camera angles (first-person shooter). Many of these genres are poor classes because they lump together very different games (e.g. platformers) or do not support the inferences we want to make (e.g. can my partner and I enjoy playing this together?) (Portnow, 2012).

Solving the game genre problem is beyond the scope of this paper. However, effectively analysing design challenges in WRPGs necessitates defining our domain of inquiry.

\section{Defining Western Role Playing Video Games}

Yee (2006) argues that people play RPGs for three reasons: experiencing the game's story, discovering new things/places, and overcoming challenges. While we agree that RPGs combine narrative, discovery, and challenge aesthetics, we associate RPGs with a wider array of elements and aesthetics, including:

- Progression: Character levelling including increasing skills or attributes and unlocking new abilities.

- Expression: (1) Numerous opportunities for player choice, especially choices among more than two options, (2) Character customization including 
appearance, gender, voice, race, abilities, attributes, sexual orientation, background and personality.

- Creation: Making or improving weapons, armour, jewellery, consumable items or other equipment; sometimes whole buildings or towns.

- Fantasy: Fantastical or futuristic settings, magical or supernatural beings or powers, and themes of good versus evil.

- Sensation: Majestic, grandiose or ostentatious environments including high mountains, impenetrable forests, enormous castles, and impossibly deep dungeons.

- Submission: Repetitive actions to gain experience, collect money, complete quests or find items for crafting.

- Puzzle: Cognitively taxing challenges both tactical (e.g. how do I defeat these enemies?) and environmental (e.g. how do I open this door?).

- Management: Organizing a large inventory of supplies and selecting equipment appropriate to different quests.

- Discovery: (1) A large open world for players to explore, (2) A large number of secrets, locations, items, events or characters to discover.

- Narrative: A main quest that encompasses the game's primary story arc and a large number of optional (side) quests.

- Challenge: Iconic bosses (exceptionally powerful enemies), which often coincide with narrative progression.

RPG subgenres differ in their emphasis rather than fundamental structure or unique elements. ARPGs (e.g. the Diablo series; Figure 2) emphasize progression, challenge and submission. Many ARPGs often use player experience points to control both when abilities are unlocked and what equipment can be used (progression) (Walker, 2001). They use random loot drops and mobs (hordes of weak enemies) to encourage grinding (submission). They often use real-time combat, difficulty scaling and even permadeath to enhance the sense of challenge. 


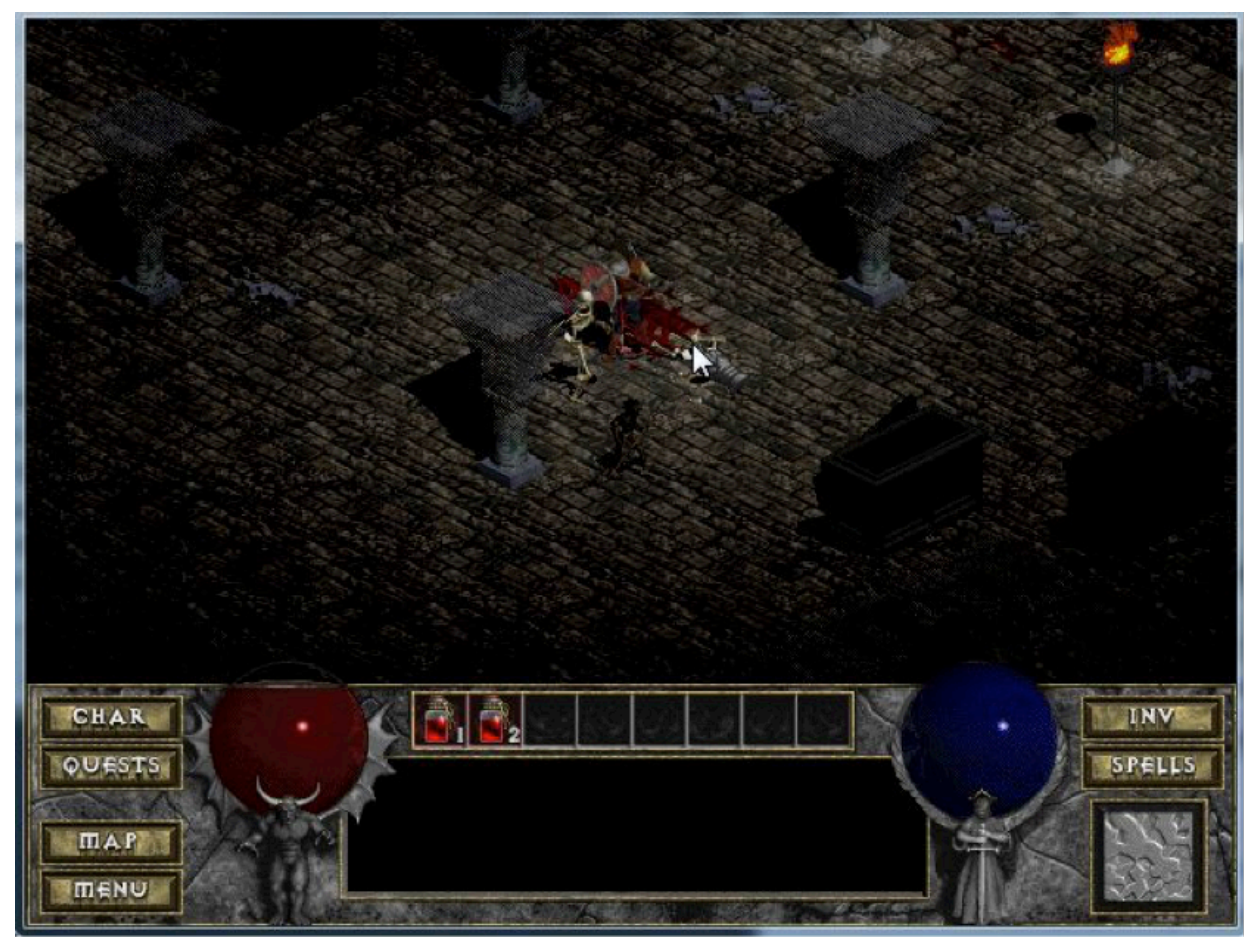

Figure 2. Diablo (1996)

JRPGs (e.g. the Final Fantasy series) similarly encourage progression, submission, and (sometimes) challenge. However, they also provide rich embedded narratives, in which, crucially, the player has little control (Newman, 2002). In a JRPG, the player lives out a largely predefined central story arc.

WRPGs also emphasise progression and challenge, but otherwise differ substantially from ARPGs and JRPGS. WRPGs have large, open (non-linear) worlds and use quests, rewards, and embedded narratives to encourage exploration (Walker, 2001). WRPGs' combination of exploration and multitudinous non-player characters (NPCs), random encounters, and interactable objects, support emergent narratives to a greater extent than ARPGs or JRPGs.

Furthermore, while JRPGs encourage the player to assume a predefined role in a predefined narrative, WRPGs encourage the player to roleplay a character of their own creation, leading to a more dominant expression aesthetic (Figure 4). For example, in the JRPG The Legend of Zelda series, the player is always Link and Link always saves Princess Zelda. Meanwhile, in the WRPG Skyrim (2011), the player can be a knight, mercenary, hunter, thief, assassin, conjurer, healer, blacksmith, etc. or any combination thereof. The player encounters numerous imperilled NPCs both good and bad and can rescue them, rob them, kill them, or ignore them and go fishing. WRPGS therefore manifest a strong expression aesthetic and emergent drama-they are what Schell (2008) called "story machines". 


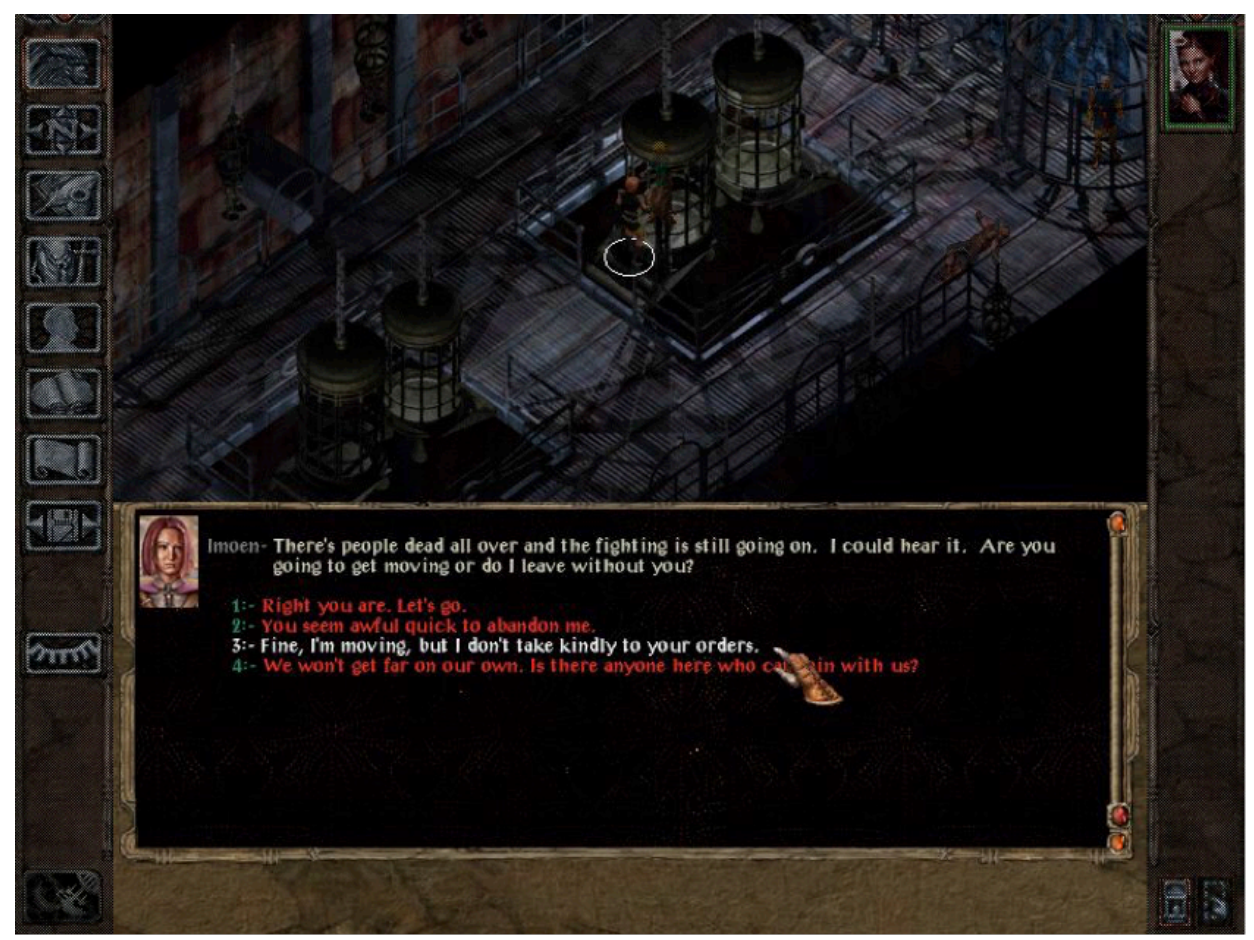

Figure 3. Dialogue in Baldur's Gate II: Shadows of Amn (2000)

In summary, RPGs of all sorts emphasise progression and challenge. In addition, ARPGs emphasise submission, JRPGs emphasise submission and (embedded) narrative, and WRPGs emphasise expression, discovery and (emergent) narrative. Based on this analysis, we can define WRPGS as follows:

Definition 1: A "Western" or "Open-World" Roleplaying Game is a video game that: encourages players to assume the part(s) of one or more virtual characters, in large open environments, with plentiful freedom of expression throughout game narratives.

In other words, a WRPG is a video game that meets three conditions:

1. The player roleplays one or more characters

2. The game has one or more large open environments, facilitating non-linear gameplay

3. The game gives the player substantial control over his or her characters (e.g. appearance, gender, name, personality) and actions (e.g. help, rob, murder, go fishing)

Here, "plentiful freedom of expression" denotes greater nuance than simply giving the player some control over quest order or splitting a game into good and evil storylines, as in the Infamous series. It means that much of a WRPG's challenge is deciding what to do rather than simply determining how to accomplish predetermined objectives. WRPGs can therefore generate the gaming equivalent of literary internal conflict; i.e. psychological struggle within a character's mind.

\section{Definition Evaluation}


To evaluate whether the proposed definition present a good class, we subject it to three tests:

1. Does it include archetypal WRPGs? Based on the analysis in Table 2, we conclude that the proposed definition includes archetypal WRPGs. Of course, space precludes a comprehensive list, but we cannot think of any obvious violations.

2. Does it exclude non-WRPGS? Table 3 shows how the proposed definition excludes different but related genres.

3. Does it support useful inferences? Identifying a game as an instance of the WRPG class supports numerous inferences about the game beyond those in the definition. For example, membership in the WRPG class implies a high probability of:
a. character customisation
b. unlockable or improvable skills and abilities
c. equipment progression, via upgrading, customisation, levelling or simply acquiring superior equipment
d. explicit or implicit decision points
e. decisions with consequences in-game or in epilogue narratives
f. combat or another basis for interpersonal or narrative conflict
g. friendly and hostile non-player characters
h. multiple overlapping narratives

Table 2

Archetypal WRPGs

\begin{tabular}{lccc}
\hline Game & Assume Role & Open Worlds & Narrative Freedom \\
\hline Dark Souls III (2016) & $\checkmark$ & $\checkmark$ & $\checkmark$ \\
Dragon Age: Inquisition (2014) & $\checkmark$ & $\checkmark$ & $\checkmark$ \\
Fable (2004) & $\checkmark$ & $\checkmark$ & $\checkmark$ \\
Fallout 4 (2015) & $\checkmark$ & $\checkmark$ & $\checkmark$ \\
Mass Effect 3 (2012) & $\checkmark$ & $\checkmark$ & $\checkmark$ \\
Skyrim (2011) & $\checkmark$ & $\checkmark$ & $\checkmark$ \\
\hline
\end{tabular}

Table 3

Related Genres

\begin{tabular}{|c|c|c|c|}
\hline Genre & Assume Role & Open Worlds & Narrative Freedom \\
\hline $\begin{array}{l}\text { JRPGS } \\
\text { (e.g. Final Fantasy series) }\end{array}$ & $\checkmark$ & sometimes & \\
\hline ARPGs & $\checkmark$ & sometimes & \\
\hline
\end{tabular}


(e.g. Diablo series)

Sandbox games

(e.g. Batman: Arkham series)

Interactive story games

(e.g. Telltale's Walking Dead

series)

Platform games

(e.g. the Rayman series)

That said, we conceive of WRPG as a fuzzy class-one whose instances have degrees of membership. For our purposes, recent instalments in the Fallout and Elder Scrolls series have a very high degree of membership in the WRPG class. For comparison, the Souls series combines elements of WRPGs and ARPGs, while the Grand Theft Auto series combines elements of WRPGs and sandbox games. Bioware's Mass Effect and Dragon Age series can be seen as "marrying western mechanics with Japanese-style character interactions" (Kaiser, 2012). 


\section{Three Challenges in WRPG Design}

\section{Bipolar Morality Scales Inhibit Ethical Reasoning}

Dungeons and Dragons table-top games are the foundation of many RPG's structure and content, including morality mechanics (Tresca, 2010). Advanced Dungeons and Dragons (1979) divided morality into two-dimensions, each with three levels (Figure $5)$. The morality scale represents concern for others versus selfishness. The legality scale represents respect or contempt for law and order. For example, a chaotic good character might break the law to help someone in need, while a lawful evil character might use the rules to exploit the vulnerable.

Table 4

Alignment in Advanced Dungeons and Dragons (1979)

\begin{tabular}{l|ccc}
\hline & \multicolumn{3}{|c}{ Morality } \\
\hline \multirow{4}{*}{ Legality } & Lawful Good & Lawful Neutral & Lawful Evil \\
& Neutral Good & Neutral Neutral & Neutral Evil \\
& Chaotic Good & Chaotic & Chaotic Evil \\
\hline
\end{tabular}

Many WRPGs contrastingly employ simple, one-dimensional, bipolar morality scales. We define a bipolar morality scale as a game mechanic where:

1. in-game morality is implemented as a one-dimensional spectrum

2. in-game actions move the player toward one end or the other

3. the player character's position on the spectrum has consequences for the game narrative, character progression or in-game events

In some games, including Fallout 3 (2008), moral actions are additive such that good actions effectively erase evil actions and vice versa. In these games, the player character typically starts in the middle of the spectrum (neutral). In other games, including Mass Effect series, moral actions make permanent contributions to reputation. In these games, the player character typically starts with no reputation and builds up fame or infamy as shown in Figure 4. Table 5 gives examples of bipolar morality scales in some well-known WRPGs. Morality scales are also common in sandbox games such as the Infamous and Far Cry series. 


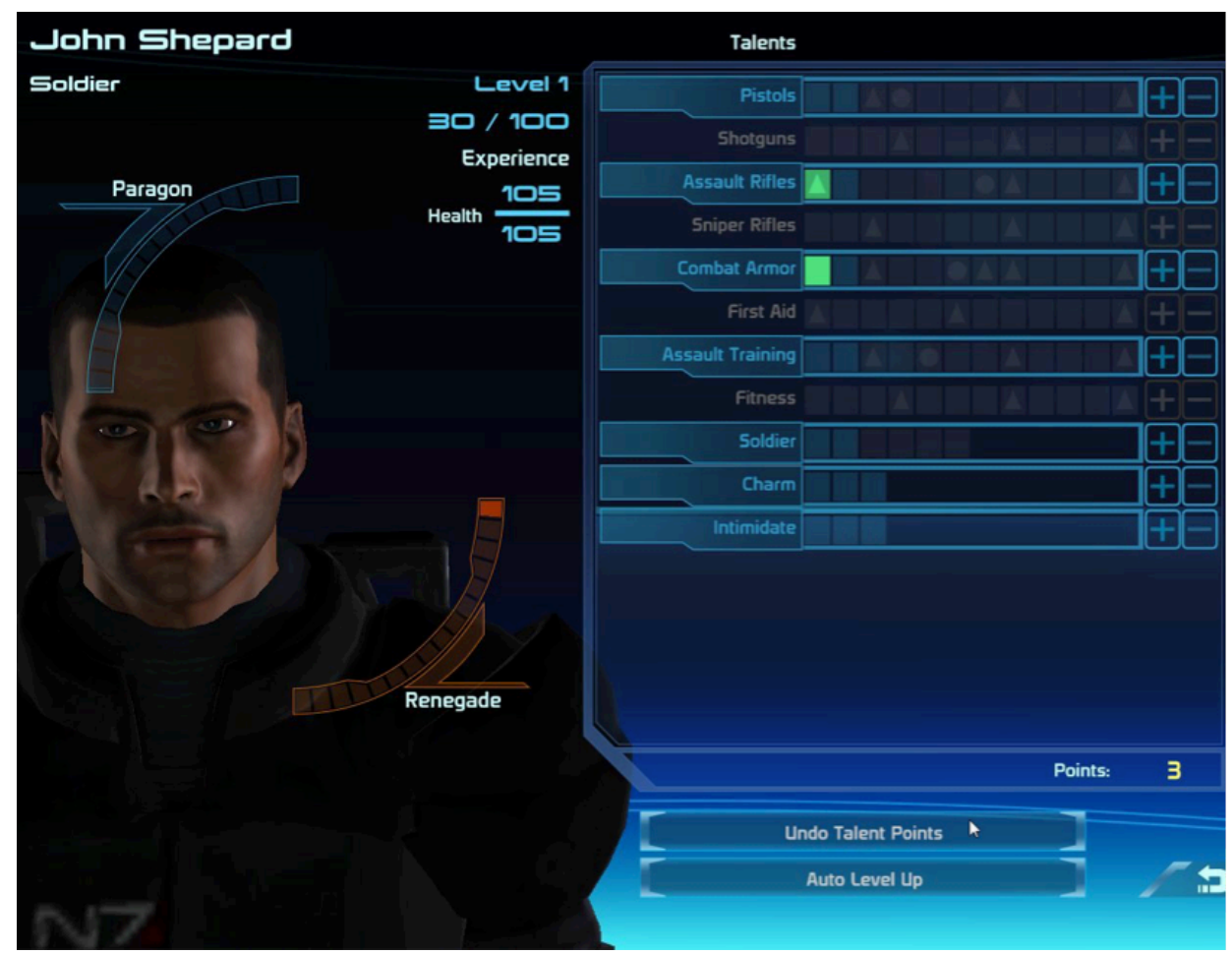

Figure 4. Example of Bipolar Morality Scales used in Mass Effect (2007)

Table 5

Examples of Bipolar Morality Scales in WRPGs

\begin{tabular}{ll}
\hline Game & Morality Scale \\
\hline Fable (2004) & Alignment: Good vs. Evil \\
Fable III (2010) & $\begin{array}{l}\text { Two alignment scales: Good vs. Evil and Purity vs. } \\
\text { Corruption } \\
\text { Fallout 3 (2008) }\end{array}$ \\
"Karma" scale: conflates lawful/chaotic with good/evil \\
Fallout: New Vegas (2010) & $\begin{array}{l}\text { Fame (good) or Infamy (evil) tracked separately for each } \\
\text { faction }\end{array}$ \\
Mass Effect series & Paragon (Lawful) vs. Renegade (Chaotic) \\
\hline
\end{tabular}

Morality scales may be used as game mechanics or narrative mechanics (Ralph \& Monu, 2015). The player's morality score may affect numerous aspects of the game including:

- abilities the player can learn

- bonuses the player receives

- available quests and rewards

- random encounters

- a character's appearance

- available game endings and epilogues

- available NPC interactions, including dialogue options and which NPCs will join the player's party 
Bipolar morality scales are attractive because they limit the complexity of programmed responses. For example, given a scale from -1000 (chaotic) to +1000 (lawful), a sheriff NPC might be programmed to attempt an arrest for any score less than 0 , and do nothing otherwise. A game designer adopting the alignment system shown in Table 4 might feel compelled to consider nine scenarios for many interactions, making the game much more complex. Morality scales also give the player some control over the story and may improve re-playability. For instance, a chaotic character may experience substantially different narratives than a lawful character.

Bipolar morality scales are, however, problematic in three main ways:

1. Bipolar morality scales discourage complex moral reasoning. One of the most engaging aspects of many WRPGs is situated moral decision-making under incomplete information. For example, Mass Effect 3 (2012) presents the opportunity to develop a cure for a bioweapon. If the player cures the bioweapon, he or she loses the support of one faction and possibly saves a race from extinction. If the player does not cure the bioweapon, he or she loses the support of another faction and possibly sets up future interstellar war. Decisions like these form some of the most engaging and memorable moments in the Mass Effect franchise. Suppose, however, a game ties advantageous skills, rewards and endings to reaching one end of a bipolar morality scale. This encourages players to choose a side (e.g. lawful) and then mindlessly select all consistent dialogue and actions for the rest of the game. Instead of asking, "which of these options do I believe is ethical?" or "which of these options is consistent with the character I'm roleplaying", the players asks, "which of these is the lawful option?" This undermines the moral reasoning experience the game developers were attempting to create.

2. Bipolar morality scales undermine immersion and emergent narratives. Suppose someone roleplaying a lawful-good character discovers bandits attacking a merchant caravan. Wanting to help, she attacks the bandit, but accidentally kills ones of the merchants. After the battle, the player finds a powerful weapon on one of the dead merchants. Reasoning that she can do much good with this weapon, she takes it. The game notifies the player that both accidentally killing the merchant and taking the item have reduced her karma score. This breaks immersion. The player asks, "how is this fair?" Instead of asking, "what is the ethical thing to do?" the player begins wondering "is that item marked as owned?" The game feels less like real life and more like a game.

3. Bipolar morality scales discourage roleplay. Suppose the player is roleplaying a neutral-good character in a game with a lawful vs. chaotic morality scale. The player explores the world, helping people legally (e.g. fixing the broken water pipes) and illegally (e.g. stealing needed medicines from the local crime lord). The player receives regular notifications of karma gains and losses, orthogonal to the player's internal moral reasoning and roleplay. This mismatch between the player's alignment and the morality scale mechanic 
suggests that the player is playing the game incorrectly somehow, discouraging meaningful roleplay.

In summary, bipolar morality scales, as implemented in contemporary WRPGs, inevitably lead to conflicts between players' ethical analyses and morality mechanics. This is practically unavoidable because there exists neither a single, objectivelycorrect system of ethics nor a single, objectively correct interpretation of a given situation. When moral performance is linked to rewards, the player is further discouraged from case-by-case decision-making.

Tyranny (2016) provides a particularly good example of handling morality well. In Tyranny, a player can gain "Favor" and/or "Wrath" by interacting with characters and factions (Figure 5). The character can gain independent reputations with many different characters and factions in the game rather than a global reputation, and characters can only gain Favor or Wrath when they interact with characters or members of factions. This gives the reputation system multiple moral stances since each reputation is based on not only on the player's actions but also the faction or NPC's morality. For instance, saving a village from starvation might simultaneously gain Favor with a faction who views this as just while gaining Wrath with another faction that wanted chaos in the village to topple the local government. Meanwhile, a player could gain both Favor and Wrath with a character who is a member of the village but is not pleased that his rations were raided to save the village. However, Tyranny problematically ties reputations to player skills and abilities:

When it rewarded me with skills based on my reputations with factions like the staunchly disciplined Disfavored or the ragtag Scarlet Chorus, which welcomes captured prisoners into its ranks, I sometimes found myself choosing answers that would eventually lead to a new skill rather than what I'd actually say in character. That derailment of the roleplaying spirit is one of the few weaknesses of Tyranny. (Johnson, 2016)

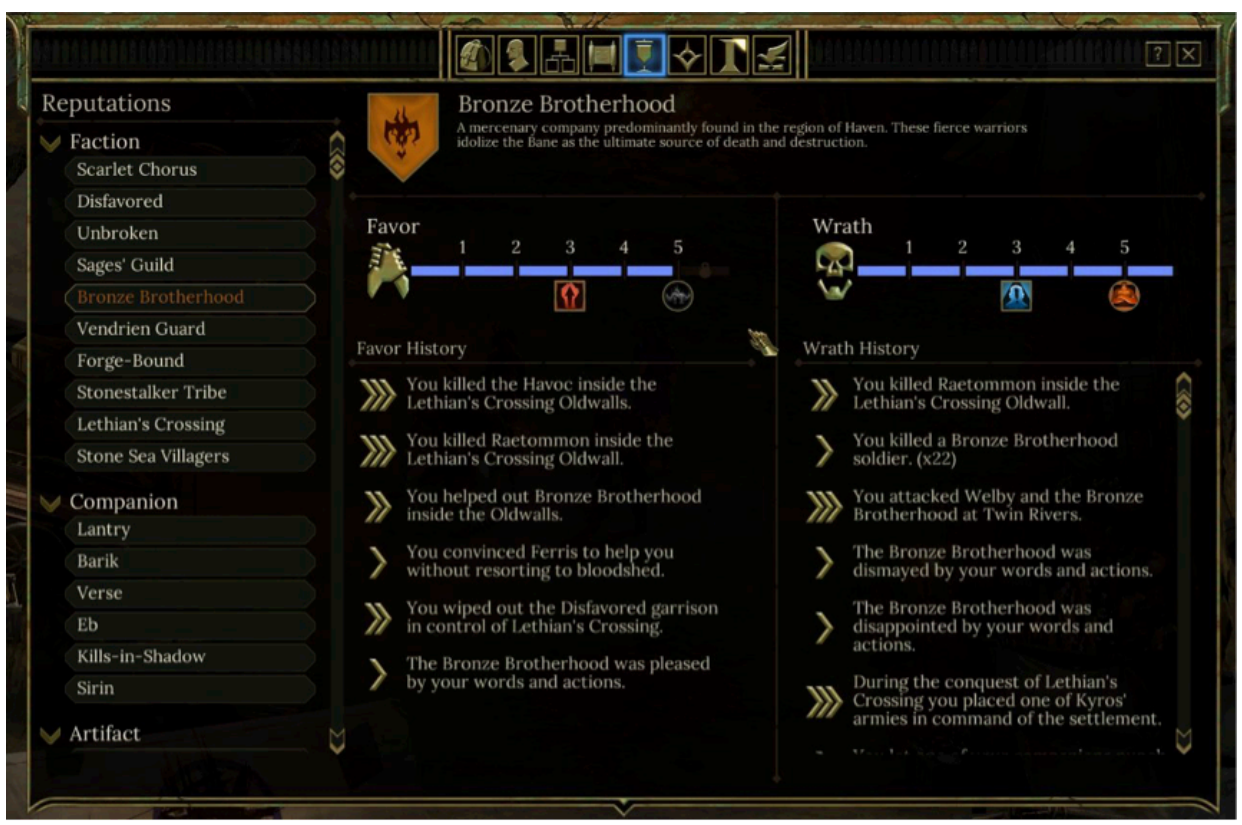

Figure 5. Tyranny (2016) reputation/morality system 
The approach to morality taken by WRPGs (and many other RPGs and Sandbox games) vary on at least five dimensions. We present these dimensions as a set of questions, which game designers might use to specify their approach to morality:

1. What are we trying to achieve by introducing morality mechanics (e.g. encourage roleplay, engaging decision-points, replayability, realism)?

2. How many and which alignment dimensions should we use (e.g. lawful/chaotic, good/evil, righteous/corrupt)?

3. What is the scope of the alignment scores (e.g. global, faction, individual NPC)?

4. Are contributions to alignment permanent (i.e. do present good deeds erase past crimes or does the sum of the player's deeds combine to form reputation)?

5. What are the consequences of moral actions-both narrative (e.g. different game endings, epilogues, NPC interactions) and ludic (e.g. available skills, abilities, items, bonuses, quests)?

In our experience, however, the most engaging and memorable moral choices in games are ones where the challenge of choosing the right course of action overwhelmed any specific ludic consequences. Many good examples of these can be found in Telltale Games' The Walking Dead (2012), The Wolf Among Us (2013) and even Tales from the Borderlands (2014). A specific example from a WRPG is the decision (mentioned above) whether to cure the bioweapon in Mass Effect 3 (2012). Therefore, if the goal is to engage players with interesting decisions or encourage roleplay, implementing an alignment system with ludic consequences may be counterproductive. It would be better to focus on crafting morally ambiguous decisions with specific narrative consequences.

Moral decisions can be made more interesting by presenting three or more options, none of which maps cleanly into 'good', 'evil', 'lawful', etc. For example, the choice of whether or not to rescue the innocent child from the terrible monster is not as interesting as the choice of whether to (1) allow your companion to go on a suicide mission to save a village of innocent people, (2) let the village burn, (3) commit your entire force to save the (inconsequential) village, which will cause a different companion to abandon your cause.

If, however, game designers have a compelling reason to quantify morality, many immersion-breaking experiences can be avoided by:

1. Using two or more alignment dimensions (e.g. lawful/chaotic and good/evil)

2. Setting scope at the faction or individual NPC level, rather than having a single global morality score. This approach can be improved by basing reputation predominately on witnessed actions

3. Focus on narrative consequences and NPC interactions rather than unlocking abilities or items with morality scores 
Beyond avoiding oversimplified morality mechanics, WRPGs could be an excellent vehicle for explicitly exploring the tension between morality and legality. Developers could create quests where players have to break laws to act morally, or where staying within the law entails immoral decisions. A good but illegal act might lead others to break the player out of prison, while an immoral but legal act could lead others to shun the player. Done well, this should intensify immersion and the player's perception of the game world's depth.

\section{Quest Hubs Inhibit Exploration}

In RPG vernacular, a quest is a series of tasks that a player performs to advance the game or receive some reward. Quests are both narrative mechanics and game mechanics because they not only form part of a game's story but also present and structure challenges. Many WRPGs divide quests into different categories, including main quests (necessary to complete the game); side quests (substantial but unnecessary quests); minor quests (tasks with minimal narrative content); and unmarked quests (quest-like structures that are not listed or recorded in quest logs, diaries or maps).

Placing quest starting points is important and difficult for at least four reasons:

1. Many WRPGs use quests to organise much of their content. It is therefore important that players can find most of the quests.

2. Many WRPGs use quests to encourage and direct exploration. Players often have to find or explore a new area to complete a quest. The main quest line often directs the player through the most important regions of the game world. Quests can send the player back to a previously explored region, especially if the region has since changed.

3. Players can easily get lost in large, open game worlds. Not knowing where to go next disrupts flow, a mental state characterised by focus, enjoyment and strong performance (Csikszentmihalyi, 2000). Many WRPGs therefore provide several navigation mechanics including a compass, a map with clearly marked quest-givers and objectives, and even indications showing the shortest path to the current objective.

4. Haphazardly dumping quests on the player would break immersion. Players typically find quests at specific locations in the game world, sometimes by speaking to an NPC, finding an object or simply arriving at a location. Games do not just give the player a complete list of quests from the outset because this would be overwhelming and frame-breaking.

These valid design considerations underlie a common pattern in Action RPGs: quests are clustered into clearly marked quest hubs-areas of a game world with a high concentration of quest starting points (e.g. towns). Quests are given by clearly marked characters. Players swoop into the hub, begin all available quests and then complete quest steps geographically. Quest markers and other navigation mechanics inform the player precisely where to travel to complete quests, avoiding the tedium of looking around. The last quest directs the player to the next quest hub. This pattern 
works in ARPGs because it maximizes time in the action, consistent with the challenge aesthetic.

However, this pattern is problematic in WRPGs for three reasons:

1. It interferes with the drama aesthetic. Hubs full of quests and clearly marked locations encourage players to complete multiple quests geographically rather than one quest at a time. This strategy leads to a hodgepodge of overlapping, incoherent storylines, undermining the drama aesthetic. Moreover, overprescribing player actions through quest hubs and navigation mechanics reduces opportunities or emergent narrative.

2. It interferes with the discovery aesthetic. Clustering quest givers into hubs and precisely indicating quest givers and paths often engenders a sense of being led through the game. In our experience, following a predefined, highlighted path does not feel like exploring. Indicating a destination on a map is one thing, but constantly dictating where to go and how to get there makes a large open world feel suspiciously linear.

3. Attempting to cluster quests may furthermore increase repetitiveness as most quests begin with the same person-in-trouble. New quests are rarely found in the middle of current quests. Quests rarely interrupt each other. Repetitive quests can work in ARPGs because they are consistent with the submission aesthetic; however, they interfere with both the discovery and drama aesthetics central to WRPGs.

In summary, quest hubs and strong navigation mechanics align well with challenge and submission aesthetics by keeping the player flowing through predefined challenges. However, they misalign with discovery and drama aesthetics by discouraging exploration and inhibiting coherent storytelling and emergent narrative. This aesthetic conflict is central to the different appeals of ARPGs and WRPGs.

Based on our experience with existing WRPGs and similar games, we have several suggestions for improving alignment between quest distribution/navigation mechanics and discovery/drama aesthetics:

- Fill the game with exploration cues; that is, hints about hidden and distributed quests. For example, a billowing cloud of smoke in the distance is an unsubtle hint to go see what's burning. Similarly, a village of people who will not speak to the player except to indicate that they are terrified of ghosts coming from the abandoned mine to the west suggests looking for the mine without explicit quest givers or paths. Hints can be hidden in books, scrolls, dialogue and other narrative mechanics.

- Distribute side quests throughout the game world. Trust players to find them.

- Hide quests in remote locations. Climbing a precarious hill to get a good look around, only to find a quest at its apex, makes for a pleasant surprise.

- Distribute quests through random encounters. 
- Tie quests and their locations to player actions. For example, aligning with the Brotherhood of Steel in a Fallout game could allow the player to access quests over Brotherhood radio stations.

- Have non-player characters wave, call out or even run up to the player to ask for help. This is more immersive than map markers.

- Have some enemies randomly drop quest-giving items (e.g. notes, journals, mysterious talismans) when they are defeated.

- Limit the number of quests simultaneously available to the player.

- Introduce a way of identifying unfinished quests (e.g. a magic compass) late in the game, possibly after completing a game's main quest line.

- Introduce multiple start points for the same quest, such that a quest with a well-hidden start point early in the game has a more obvious start point later in the game.

The final recommendation-multiple start points per quest-is especially powerful. Suppose we have an interesting quest with a reward that would be especially useful early in the game. Hiding a quest start point early in the game rewards good exploration, while having a more obvious start point later in the game reduces the probability that less discovery-oriented players will miss an interesting piece of content, even though the reward will be of little use. The quest-finding magic compass is just a specific implementation of multiple start points.

\section{Oversimplified Difficulty Scaling}

Contemporary WRPGs commonly employ at least two kinds of difficulty scaling. Because players vary widely in skill and experience, many WRPGs have a difficulty setting. Players can choose to play the game on easy, normal, hard, etc. as suits their abilities. Meanwhile, regardless of chosen difficulty level, many WRPGs scale enemies as the player levels (i.e. becomes more powerful). Both types are problematic.

One common way to give the player some control over difficulty is to link a difficulty setting to enemy attack and defense coefficients. At harder difficulty settings, enemies can both deal and take more damage. This leads to immersion-breaking experiences. For example, when playing Fallout 3 (2008) at maximum difficulty, the player encounters lightly armoured humans who can shrug off direct hits by rockets, grenades and landmines. This bullet-sponge dynamic shatters suspension of disbelief in games with otherwise semi-realistic combat. While less obvious in fantasy and far-future settings where enemies have magical or technological shields, recognising a bullet sponge damages immersion by reminding the player that it's only a game.

Approaches to scaling enemies with player levelling are more complicated. Older RPGs, including Final Fantasy (1987) organised difficulty geographically; that is, enemy levels were determined by where they were in the open world. This made the open world seem too linear-players would wander into a new area only to be immediately eaten by some unassailable monster. Newer RPGs consequently began 
levelling enemies linearly with the player's level. The Elder Scrolls IV: Oblivion (2006) adopted this strategy to heavy criticism (e.g. Pitts, 2006). Two main problems emerged: (1) without a careful levelling strategy, the player would become effectively weaker with every level-up, and (2) players would encounter very powerful enemies that look and act exactly like very weak enemies. For instance, a player might defeat a dozen dragons only to be slain by an overgrown moth. Just as geographic scaling undermined the discovery aesthetic, player scaling undermines the progression aesthetic. Easily defeating enemies that were previously challenging reminds players how far they have come.

Many WRPGs including Dragon Age: Origins (2009) therefore moved to a hybrid approach called bounded level scaling. Using a bounded level scaling mechanic, enemies will scale with the player within a certain range, usually reflecting expectations about when players will experience that section of the game. For example, a dragon's level may be set to the player's level plus two, with a minimum of 15 and maximum of 25 . While bounded-level scaling ameliorates many of the problems with both geographic and player-level scaling, it does not address the more fundamental issue with scaling difficulty based only on combat.

WRPGs are concerned with not only challenge and progression but also discovery, drama, expression, creation, fantasy, management, and puzzles. Scaling combat difficulty based on attack and defense is well aligned with challenge; however, it ignores the other key aesthetics and the potentially rich interaction between combat and non-combat challenges.

One of the richest approaches to difficulty we have seen is the introduction of "Hardcore Mode" in Fallout: New Vegas (2010). In hardcore mode (Figure 6), players must eat, sleep, and drink regularly to survive; ammunition has more realistic weight; healing and de-radiating items work slowly; crippled limbs are more difficult to repair; and companions can permanently die. These tweaks enhance difficulty in more realistic, immersive and interesting ways than turning enemies into bullet sponges. 


\section{— Hardcore Mode}

Fallout: New Vegas allows you to play in a new

Hardcore mode that greatly increases the

challenge of the game. In this mode, Stimpaks heal

over time and cannot mend broken limbs, Rad-Away

removes radiation over time, ammunition has

weight, and dehydration is a constant concern.

This mode is only recommended for advanced

players.

You may turn Hardcore mode on or off at any time

in the Gameplay menu, but if you activate Hardcore

mode now and maintain it through the end of the

main storyline, you will receive a special reward.

Would you like to activate Hardcore mode?

\section{No (Recommended)}

\section{YeA}

Figure 6. Description of Hardcore Mode In Fallout: New Vegas (2010)

Generalising the features of hardcore mode and difficulty tweaks in numerous usergenerated game modifications (cf. Scacchi, 2011), we advance the following suggestions for richer difficulty increases.

- Puzzles:

○ increase puzzle complexity

- give fewer hints

- increase puzzle frequency (e.g. a normal door in easy mode might require a puzzle to unlock in hard mode)

- add impossible battles or obstacles to necessitate stealth or more creative strategies

$\circ$ increase the difficulty of minigames (e.g. lock-picking)

- Items and trade:

- reduce the weight or volume of items characters can carry

- make useful items more expensive and scarce

- make equipment degrade more quickly

- reduce merchants' cash on hand

- reduce the quality of merchants' stock

- make beneficial items act slower and harmful items act faster

○ prevent or discourage stockpiling equipment

- Crafting: 
- increase the materials required to craft or improve items

- increase difficulty of obtaining recipes or plans for craftable items

o introduce crafting minigames such that the player can fail to craft an item

- Navigation:

- remove or encumber navigation mechanics including quest markers and maps

- remove the shimmer often used to identify items that can be picked up

o introduce realistic consequences of travelling long distances, e.g., dehydration, starvation and exhaustion

- Combat:

- add time limits to turn-based mechanics

- switch from assisted aim to free aim

- make more powerful weapons more difficult to use

- magnify fear, impaired vision or disorientation mechanics that temporarily interfere with character control

- add more realistic sway, sights and trajectory to projectile weapons (e.g. aiming above distant targets to hit them)

$\circ$ generally increase player fragility instead of making enemies tougher

- Companies(/followers/allies) and NPCs:

- allow allies to be killed

- make allies more prone to abandon or betray the player

- make allies more likely to set off traps or give away location

- make allies less effective in combat

- make NPCs react more negatively to poor dialogue choices (e.g. by refusing to talk to the player or give quests)

Of these recommendations, increasing puzzle complexity may be the most practically difficult. However, many puzzles can be straightforwardly scaled. For example, in Mass Effect 3 (2007), the player hacks a computer by solving the classic Towers of Hanoi puzzle. Simply adding disks can increase the difficulty of the puzzle for many players. Game designers may draw inspiration from many such scalable mathematical puzzles.

Obviously, no one game would implement all of these suggestions, and game designers have to weigh any specific approach in the context of the game at hand. Approaches should only be used when their resultant increase in depth justifies the corresponding increase in complexity without undermining the game's core aesthetics.

\section{Conclusion}

In summary, this paper provides two main contributions. It first defines a Western or Open-World RPG as a video game that: encourages players to assume the part(s) of one or more virtual characters, in large open environments, with plentiful freedom of expression throughout game narratives. In a sense, WRPGs are the only RPGs that markedly encourage creative and divergent roleplay. 
Our second contribution is delineating three enduring challenges in WRPG design: Bipolar morality scales, quest hubs and oversimplified difficulty scaling. We further suggest concrete approaches to mitigating these challenges, including (1) replacing explicit morality mechanics with consequential moral choices; (2) distributing quests throughout the game world with more exploration cues; and (3) scaling non-combat difficulty using puzzle complexity, resource scarcity and NPC behavior.

These contributions should be considered in light of three main limitations. First, this paper presents suggestions based on anecdotal experience, not empirically-tested solutions. Second, the design problems and recommendations discussed are not comprehensive-surely there are other common problems and possible solutions we have not considered. Third, as terms have no objectively correct definition, our suggested classification of WRPGs is good only insofar as it helps reduce cognitive load and make useful inferences.

These limitations notwithstanding, our contributions are useful for both academics and practitioners. Clear genre definitions help academics more precisely specify the domain of their research and claims. Just as a literature professor might discuss " $19^{\text {th }}$ century French romances", not "novels," a professor of game studies should discuss "WRPGs released between 2004 and 2014," not "games". Contemporary video games are far too diverse to support the kind of sweeping generalisations seen all too often in the media, e.g. "Do video games lead to violence?" (Scutti, 2016).

Meanwhile, inexperienced game developers may find here a useful summary of common problems not well-treated elsewhere, along with many techniques for overcoming them. For more experienced developers, we provide a checklist of ideas both for trying directly and for inspiring further innovations. In both cases, these are suggestions that should be tried and playtested to determine whether they are appropriate for any specific game or helpful at all.

In conclusion, we find WRPGs more meaningful when the player consistently roleplays a character of their own creation. This is what sets them apart from practically all other games, which offer only one or a few predefined roles to play out, and yet even the best WRPGs often sabotage creative roleplay in service to competing aesthetics. The effect of creative roleplay on enjoyment, immersion and flow is a potentially fruitful area for future research. 


\section{References}

Bailey, K. (2012). These Western-developed JRPGs deserve your time. Retrieved December 19, 2016, from https://www.engadget.com/2012/09/12/thesewestern-developed-irpgs-deserve-your-time/

Csikszentmihalyi, M. (2000). Beyond boredom and anxiety. Jossey-Bass.

Deterding, S., Dixon, D., Khaled, R., \& Nacke, L. (2011). From game design elements to gamefulness: defining "gamification." In Proceedings of the 15th International Academic MindTrek Conference (pp. 9-15). ACM.

Fine, G. A. (2002). Shared Fantasy. University of Chicago Press.

Grandstaff, M. (2013, June 10). E3 2013: ESO Arriving on PlayStation 4, Xbox One! Retrieved 2013, from http://www.bethblog.com/2013/06/10/e3-2013-esoarriving-on-playstation-4-xbox-one/

Hunicke, R., LeBlanc, M., \& Zubek, R. (2004). MDA: A formal approach to game design and game research. In Proceedings of the AAAl Workshop on Challenges in Game Al. San Jose, CA: AAAl.

Jenkins, H. (2004). Game design as narrative architecture. In N. Wardrip-Fruin \& P. Harrigan (Eds.), First Person: New Media as Story, Performance, and Game (pp. 118-130). MIT Press.

Johnson, L. (2016, November 11). Tyranny Review: Making the old feel new again. Retrieved January 1, 2017, from http://me.ign.com/en/tyranny/126527/review/tyranny-review

Kaiser, R. (2012, December 21). 2012: the year in RPGs. Retrieved September 21, 2015, from http://www.engadget.com/2012/12/21/2012-the-year-in-rpgs/

Newman, J. (2002). The myth of the ergodic videogame. Game Studies 2(1).

Parsons, J., \& Wand, Y. (2008). Using Cognitive Principles to Guide Classification in Information Systems Modeling. MIS Quarterly, 32(4), 839-868.

Pearce, C. (2004). Towards a game theory of game. In N. Wardrip-Fruin \& P. Harrigan (Eds.), First Person: New Media as Story, Performance, and Game (pp. 143-153). MIT Press.

Peterson, J. (2012). Playing at the World. Unreason Press.

Pitts, R. (2006, August 4). Oblivion: The Dagobah Cave. Retrieved September 22, 2015, from http://www.escapistmagazine.com/articles/view/videogames/editorials/op-ed/992-Oblivion-The-Dagobah-Cave

Portnow, J. (2012, October 17). Extra Credits: Aesthetics of Play. Retrieved November 30, 2014, from http://www.pennyarcade.com/patv/episode/aesthetics-of-play 
Ralph, P., \& Monu, K. (2015). Toward a unified theory of digital games. The Computer Game Journal, 4(1), 81-100.

Rosch, E. (1978). Principles of Categorization. In E. Rosch \& B. Lloyd (Eds.), Cognition and Categorization (pp. 27-48). Hillsdale, NJ, USA.

Scacchi, W. (2011). Modding as an Open Source Approach to Extending Computer Game Systems. In Open Source Systems: Grounding Research (Vol. 365, pp. 62-74). Berlin: Springer.

Schell, J. (2008). The Art of Game Design: A book of lenses. Morgan Kaufmann.

Scutti, S. (2016). Do video games lead to violence? Retrieved January 1, 2017 from http://www.cnn.com/2016/07/25/health/video-games-and-violence/index.html

Tresca, M. J. (2010). The Evolution of Fantasy Role-Playing Games. McFarland.

Valve. (2017). Top 100 Best Sellers of 2016. Retrieved January 1, 2017, from http://store.steampowered.com/sale/2016 top sellers/

Walker, M. H. (2001). The Video Game Almanac. Mars Pub Inc.

Yee, N. (2006). Motivations for play in online games. CyberPsychology \& Behavior, $9(6), 772-775$.

\section{List of Figures}

Figure 1. The Unified Theory of Digital Games (Ralph \& Monu, 2015) .................. 3

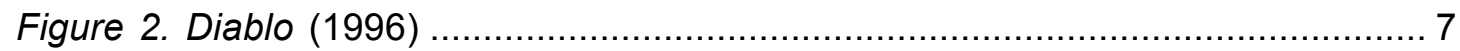

Figure 3. Dialogue in Baldur's Gate II: Shadows of Amn (2000).......................... 8

Figure 4. Example of Bipolar Morality Scales used in Mass Effect (2007) ............ 12

Figure 5. Tyranny (2016) reputation/morality system ......................................... 14

Figure 6. Description of Hardcore Mode In Fallout: New Vegas (2010) ................... 20

\section{List of Tables}

Table 1. Definitions (adapted from Ralph \& Monu, 2015) .................................... 4

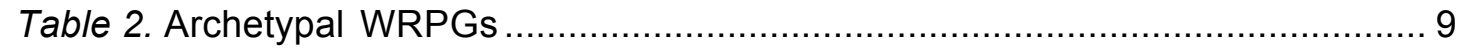

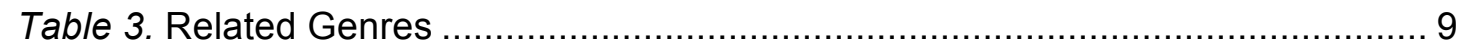

Table 4. Alignment in Advanced Dungeons and Dragons (1979) .......................... 11

Table 5. Examples of Bipolar Morality Scales in WRPGs ..................................... 12 


\section{About the Authors}

\section{Paul Ralph}

Dr. D. Paul Ralph is an award-winning scientist, author and consultant, a senior lecturer in computer science at The University of Auckland and a visiting assistant professor of management at the University of British Columbia. His research centres on the empirical study of software and game development, including projects, processes, practices, tools and developer cognition, socialisation, productivity, creativity, wellbeing and effectiveness. Dr. Ralph's research has been published in premier software engineering and information systems outlets including the International Conference on Software Engineering, the International Conference on Information Systems, the Journal of the Association for Information Systems, and Information and Software Technology. Additionally, he has written editorials on technology, education and design for influential outlets including Business Insider, Lifehacker and The Conversation. Dr. Ralph is the founding director of the Auckland Game Lab, co-founder of the AIS Special Interest Group for Game Design and Research (SIGGAME) and a member of the IEEE Technical Council on Software Engineering and ACM Special Interest Group on Software Engineering. Previously, he was a lecturer at the Lancaster University Management School, the highest rated management research institution in the United Kingdom. Paul holds a PhD in Management from the University of British Columbia.

Contact:_paul@paulralph.name

\section{Kafui Monu}

Dr. Kafui Monu is an Assistant Professor of Business Informatics at the University of Northern British Columbia. His research centres on improving human-computer interaction by better understanding users and their needs. In service to this research, he has developed tools and techniques that have been used to understand information systems in financial scandals, consumer markets, and disaster management. Dr. Monu is a co-founder, and the current President, of the AIS Special Interest Group for Game Design and Research (SIGGAME). He has also acted as track chair for game and gamification studies at several conferences including the IEEE Conference on Business Informatics, the Hawaii International Conference on System Sciences, and the Americas Conference on Information Systems. Kafui holds a $\mathrm{PhD}$ in Management Information Systems from the University of British Columbia.

Contact: kafui.monu@unbc.ca 


\section{The Journal of Creative Technologies (JCT)}

https://ctechjournal.aut.ac.nz

ISSN: $2230-2115$

Colab, Auckland University of Technology, New Zealand

Creative Commons Attribution 4.0 International License (CC-BY)

All articles published in The Journal of Creative Technologies (JCT) from Issue 4 onwards are licensed under a Creative Commons Attribution 4.0 International License (CC-BY). The copyright of the material remains with the author(s), and third-parties are granted permission to use, shared, and adapted the material, provided the original work is appropriately attributed.

The Journal of Creative Technologies (JCT) is an online, open access, peer-reviewed journal for the publication of research and innovation about new technologies, creative practices, and critical theories. The journal aims to explore applied, methodological and theoretical perspectives on emergent technological platforms and strategies through thematically focused issues.

$J C T$ is a research communication platform published by Colab at the Faculty of Design and Creative Technologies, Auckland University of Technology. 